\title{
Social Media Use and Empathy: A Mini Meta-Analysis
}

\author{
Shu-Sha Angie Guan1, Sophia Hain ${ }^{2}$, Jennifer Cabrera ${ }^{3}$, Andrea Rodarte1 \\ ${ }^{1}$ California State University, Northridge, USA \\ ${ }^{2}$ University of Illinois at Urbana-Champaign, Champaign, USA \\ ${ }^{3}$ University of California, Irvine, USA \\ Email: angie.guan@csun.edu
}

How to cite this paper: Guan, S.-S.A., Hain, S., Cabrera, J. and Rodarte, A. (2019) Social Media Use and Empathy: A Mini MetaAnalysis. Social Networking, 8, 147-157. https://doi.org/10.4236/sn.2019.84010

Received: August 19, 2019

Accepted: October 6, 2019

Published: October 9, 2019

Copyright (c) 2019 by author(s) and Scientific Research Publishing Inc. This work is licensed under the Creative Commons Attribution International License (CC BY 4.0).

http://creativecommons.org/licenses/by/4.0/

\begin{abstract}
Concerns about the effects of social media or social networking site (SNS) use on prosocial development are increasing. The aim of the current study is to meta-analytically summarize the research to date $(k=5)$ about the relationship between general SNS use and two components of empathy (i.e., empathic concern and perspective-taking). Random effects meta-analyses showed that SNS use was significantly and positively related to affective empathy though only marginally related to cognitive empathy. These effects were generally small in size and do not establish causality. Future research should explore how specific behaviors are related to different forms of empathy.
\end{abstract}

\section{Keywords}

Social Media, Empathic Concern, Perspective-Taking

\section{Introduction}

Understanding how individuals relate to and empathize with one another is foundational to the scientific study of social development. Empathy, the ability to understand the emotions of others (the cognitive component of perspective-taking) and share in them (the affective component of empathic concern), is believed to underlie the human capacity to bond with offspring in parent-child attachment and cooperate with group members in ways that progress societies [1] [2]. This relational construct is believed to be the "foundation of human social experience" [3] and is linked to outcomes at the individual and societal level. For example, adolescents with higher empathy become adults with better social skills, higher civic engagement, and greater prosocial skills like helping [4] [5] [6]. Additionally, countries with higher empathy have higher levels of collectiv- 
ism, subjective well-being, prosocial behaviors, and U.S. states with higher empathy have reduced violent crime [7] [8].

However, there is growing concern that empathy is decreasing among recent cohorts of adolescents and young adults while narcissism is increasing [6]. Social media may play a role in this phenomenon. The current meta-analysis explores the relationship between social media use in daily life and the two components of empathy. We begin by discussing the history of social media or social networking sites (SNSs), linking it to the literature on empathy, outline our methodological strategy, present our results, and end with a discussion of limitations and implications. Altogether, this study will provide important insight into the effects of media use.

\subsection{Social Networking Sites}

In the last two decades, technological advances and social media have made it easier to "connect" with others. Social media is part of what researchers broadly call "new media" or "digital media" and has several affordances that separate it from older forms of media (e.g., television, radio, newspapers), such as pervasiveness, disembodiment, interactivity, and asynchronicity [9] [10] [11]. Social media sites, or social networking sites (SNSs), are defined as Web-based services that: 1) individuals can use to construct public or semi-public profiles within a bounded system; 2) identify other users with whom they share a connection; and 3) view and traverse their and others' lists of connections [12]. Indeed, in the late 1990s, the first recognized sites (http://sixdegrees.com, https://www.classmates.com) were aimed at connecting friends. Later, sites like LiveJournal (1999) and Friendster (2002) provided a means for individuals to share profiles and personal opinions. These characteristics and affordances of today's most popular SNSs, like Facebook (2004), Twitter (2006), and Instagram (2010), likely shape the values and capacities formed from time online.

\subsection{Media-Empathy Paradox}

Although digital media can facilitate relationship formation and maintenance, there is recent evidence of a media-empathy paradox, the irony that a tool created for social connection may be reducing connective capacities [13] [14]. For example, an analysis of 72 study samples shows that survey measures of empathy have declined nearly 40\% in American young adults since 1979 and researchers point to social media as a culprit for cultivating increasing focus on the self rather than on others [14]. Not only may other-oriented traits like empathy be decreasing, but self-oriented traits like narcissism, self-esteem, and self-satisfaction are also on the rise across a similar timespan [15] [16] [17] [18]. However, it can be argued that higher self-esteem during emerging adulthood may be normative or protective [19].

To reconcile the media-empathy paradox, some social media researchers have emphasized specific online activities as an explanatory factor. For example, social digital interactions like chatting may be linked to higher empathy [20] [21]; 
whereas the affordances of SNSs that create an emphasis on and opportunities for controllable, malleable self-presentation may lead to promotion of self-interest, narcissism, and fame-orientation [14] [22] [23] [24]. Similarly, a meta-analysis of prosocial media suggests that exposure to prosocial media is linked to higher empathic concern and prosocial behaviors [25]. However, other work on SNS use found SNS activities were also positively linked to narcissism and loneliness [26] [27]. To our knowledge, there have been no meta-analyses on the relationship between general social media use and empathy. Overall, the link between SNS use and empathy is still not well established or understood.

\section{Method}

\subsection{Search Strategy}

As shown in Figure 1, electronic searches for articles and abstracts were performed in PsycINFO, ProQuest, and Google Scholar from 1990 to 2017 and again in the summer of 2019 with final searches completed by August 11, 2019. The main search strategy used combinations of keywords related to digital media (i.e., social media, social networking sites, cyberspace, online, Internet, Facebook, Twitter, YouTube, and Instagram). Media keywords were included in all combinations with empathy keywords (i.e., cognitive empathy, affective empathy, sympathy, personal distress). In addition, we cross-referenced our search with articles cited in reviews about media and prosocial outcomes [25] [28] [29]. Searches were conducted primarily by authors Hain and Cabrera. They were then collected into an electronic folder, checked for duplicates and eligibility and coded by Hain, Rodarte, and Guan. The final sample of studies included $k=5$ studies that met the inclusion criteria.

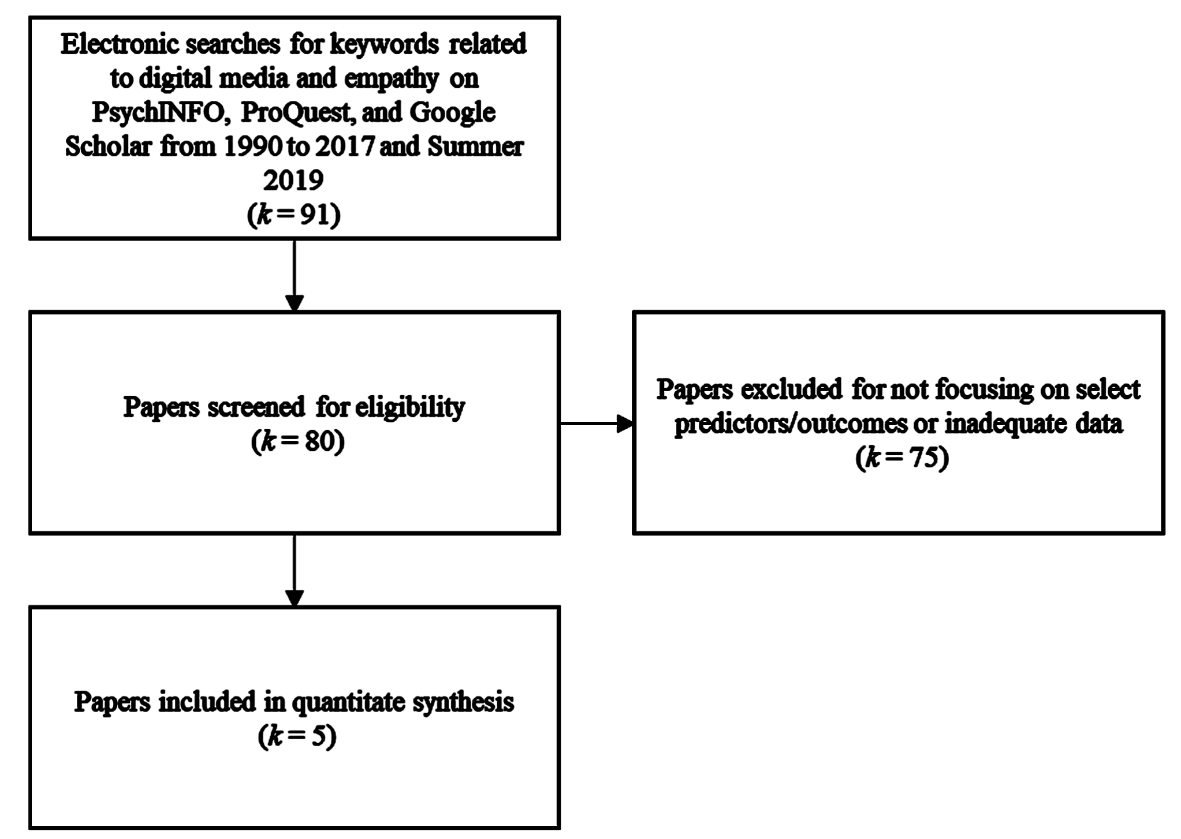

Figure 1. Flowchart of search procedures. 


\subsection{Study Selection}

\subsubsection{Empathy}

We included studies with the cognitive or affective dimensions of empathy. These factors were assessed using the Interpersonal Reactivity Index [30], Adolescent Measure of Empathy and Sympathy [31], Basic Empathy Scale [32], or the Questionnaire of Cognitive and Affective Empathy [33].

\subsubsection{Media Use}

We included different SNSs (e.g., Facebook, Twitter) and media use activities (e.g., texting, commenting, emailing). However, to narrow the scope and strengthen interpretability, we only selected for relatively active but general uses of SNSs in everyday life (i.e., profile updates, chatting, instant messaging, emailing, posting, and commenting) as measured by frequency (e.g., Use of Facebook Questionnaire [UFQ] from less than once a day to three or more times a day [21]; never to very frequently [20]) or duration (e.g., not at all to more than 10 hours a day on a "typical day" [34]). That means that we excluded studies in a specific setting such as in an educational context (e.g., assessing course discussion boards [35]), only assessed specific forms of exposure (e.g., prosocial or antisocial media; for a review see [25]), cyberbullying [36], or manipulated use [37].

\subsubsection{Data Extraction}

A rating document was prepared, revised, and used during coding. Variables coded included: study year, authors, country, participant composition, gender composition, mean age, design, media use measures, empathy measures, covariates, and test statistics. Hain and Rodarte coded each of the articles. If there was a discrepancy, Guan reviewed the article and resolved the difference. We derived a standardized coefficient $(\beta)$ from regression models or fixed effects from multilevel models [38] by multiplying the non-standardized coefficient by the standard deviation of $x$ and dividing by the standard deviation of $y$ [39] and calculated the effect size using the formula

$$
r=\beta+0.05 \lambda
$$

where $\lambda=1$ when $\beta$ is nonnegative and $\lambda=0$ when $\beta$ is negative [40]. For studies with multiple time points, the effect estimate was averaged across time points if the correlation between time points was unknown. This conservatively assumes a high correlation $(r=1)$ between time points rather than assuming no correlation but will underestimate the precision [41]. Multiple effect estimates within a study were also averaged across gender or SNS activities (e.g., chatting, posting) to create a global SNS use estimate so as not to violate the independence assumption of the meta-analysis.

\section{Results}

\subsection{Meta-Analysis}

The studies were meta-analyzed using fixed effects in which the mean effect size 
(i.e., correlation) was weighted by sample size. Study characteristics are provided in Table 1. We converted correlations into Fisher's $z$ for analysis and converted back to Pearson's $r$ for interpretation. Heterogeneity index analysis $(Q)$ was run to assess the amount of variability across studies. For affective empathy, $Q=$ 36.61, and cognitive empathy, $Q=31.75$, were both above the critical value for a $\chi^{2}(4)=9.488$ when $\alpha=0.05$ and we conclude that the studies were not homogenous and include random effects analyses.

Aggregated effect sizes are shown in Figure 2. Overall, social networking use was positively related to affective empathy, $M_{r}=0.07,95 \% \mathrm{CI}[0.04,0.10], Z=$ $4.00, p<0.01$. Additionally, social networking use was positively related to cognitive empathy, $M_{r}=0.05,95 \%$ CI $[0.02,0.08], Z=3.03, p=0.002$. Given the heterogeneity of studies, random effects were also tested and showed that SNS

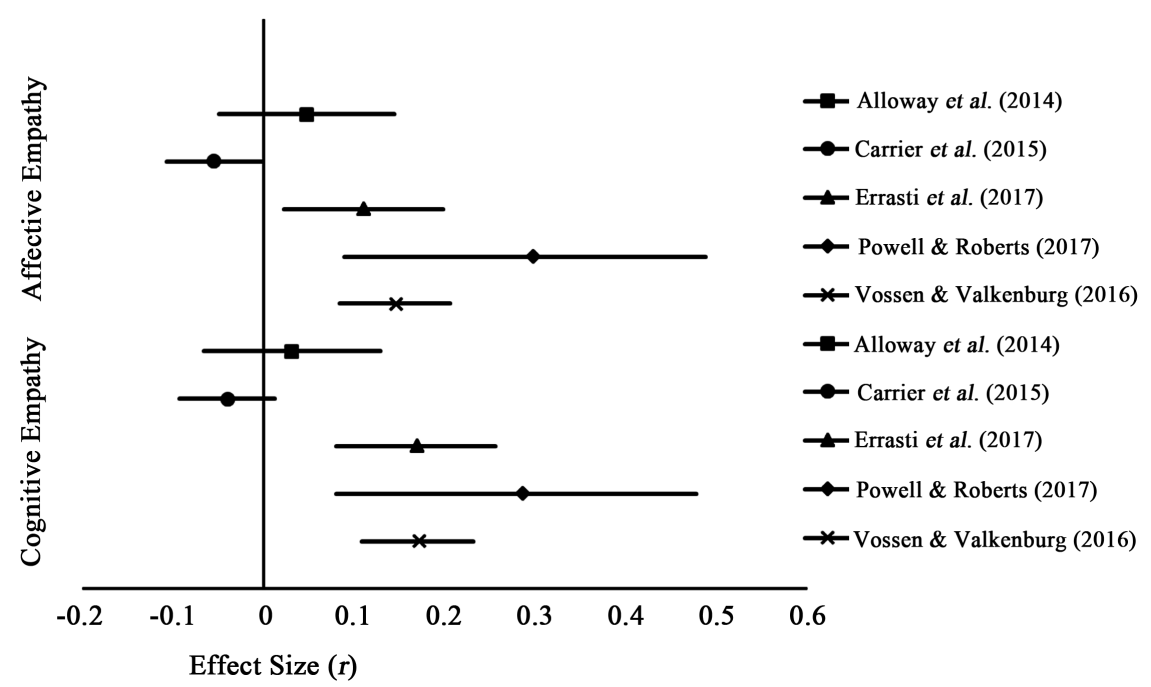

Figure 2. Meta-analysis of relationship between global social media use to affective and cognitive empathy.

Table 1. Study characteristics and effect size estimates.

\begin{tabular}{|c|c|c|c|c|c|c|c|c|c|}
\hline Study & $N$ & $\%$ Female & Ethnicities & Age & Region & Outcome & $r$ & $S E$ & Media Type \\
\hline $\begin{array}{l}\text { Alloway } \\
\text { et al. (2014) }\end{array}$ & 410 & $75 \%$ & $\begin{array}{c}73.6 \% \text { White, } 9 \% \text { African } \\
\text { American, } 6.7 \% \text { Hispanic, } \\
5.2 \% \text { Asian }\end{array}$ & $18-50$ & USA & $\begin{array}{l}\text { EC } \\
\text { PT }\end{array}$ & $\begin{array}{l}0.03 \\
0.05\end{array}$ & $\begin{array}{l}0.05 \\
0.05\end{array}$ & $\begin{array}{c}\text { FB Chat, Photo, } \\
\text { Video, Link }\end{array}$ \\
\hline $\begin{array}{c}\text { Carrier } \\
\text { et al. }(2015)\end{array}$ & 1390 & $58 \%$ & $\begin{array}{l}\text { 46.3\% Hispanic, } 21.6 \% \\
\text { Caucasian, } 14.7 \% \text { Black, } \\
\text { 12.9\% Asian, } 4.5 \% \text { Other }\end{array}$ & $\begin{array}{c}M_{\text {age }}=23.39 ; \\
S D=3.11\end{array}$ & USA & $\begin{array}{l}\text { EC } \\
\text { PT }\end{array}$ & $\begin{array}{l}-0.04 \\
-0.06\end{array}$ & $\begin{array}{l}0.03 \\
0.03\end{array}$ & General Use \\
\hline $\begin{array}{c}\text { Errasti } \\
\text { et al. (2017) }\end{array}$ & 503 & $45.9 \%$ & N/A & $14-17$ & Spain & $\begin{array}{l}\text { EC } \\
\text { PT }\end{array}$ & $\begin{array}{l}0.17 \\
0.11\end{array}$ & $\begin{array}{l}0.04 \\
0.04\end{array}$ & $\begin{array}{l}\text { FB \& Twitter } \\
\text { Frequency }\end{array}$ \\
\hline $\begin{array}{l}\text { Powell \& Roberts } \\
\qquad(2017)\end{array}$ & 100 & $50 \%$ & N/A & $18-58$ & UK & $\begin{array}{l}\text { EC } \\
\text { PT }\end{array}$ & $\begin{array}{l}0.28 \\
0.29\end{array}$ & $\begin{array}{l}0.10 \\
0.10\end{array}$ & $\begin{array}{l}\text { Duration of } \\
\text { Digital } \\
\text { Interactions }\end{array}$ \\
\hline $\begin{array}{c}\text { Vossen \& } \\
\text { Valkenburg (2016) }\end{array}$ & 942 & $50.4 \%$ & N/A & $10-14$ & Netherlands & $\begin{array}{l}\text { EC } \\
\text { PT }\end{array}$ & $\begin{array}{l}0.17 \\
0.15\end{array}$ & $\begin{array}{l}0.03 \\
0.03\end{array}$ & $\begin{array}{l}\text { Social Media } \\
\text { Frequency }\end{array}$ \\
\hline
\end{tabular}

Note: $\mathrm{EC}=$ empathic concern and PT = perspective-taking. 
use was positively related to affective empathy, $M_{r}=0.11,95 \%$ CI $[0.01,0.21], Z$ $=2.14, p=0.032$. However, SNS use was only marginally related to cognitive empathy, $M_{r}=0.09,95 \%$ CI $[0.00,0.18], Z=1.91, p=0.056$. These effects are all small in size (Cohen, 1988). Regression analyses to test the effect of percentage of gender and average age of a study on effect size were not significant, though these analyses are likely under-powered given $k=5$.

\subsection{Publication Bias}

We found no evidence of publication bias for the affective empathy effect sizes based on Egger's test, $k=5$, regression intercept $=3.72,95 \%$ CI $[-3.63,11.08], p$ $=0.394$. Additionally, the effect sizes for cognitive empathy showed no significant publication bias on Egger's test, $k=5$, regression intercept $=4.07,95 \% \mathrm{CI}$ $[-2.46,10.47], p=0.311$.

\section{Discussion}

Despite the decreases in empathy coupled with increases in media use at the societal level [13], individual social media use in terms of frequency or time spent per day appears to be related to higher levels of empathy, particularly affective empathy. Even though the associations were small, they trended positive. However, there may be some online behaviors that cultivate empathy (e.g., sharing emotions, expressing support [21]) more than others (e.g., updating profile photos [20]). In combination with emerging longitudinal evidence that social media use at one time point is predictive of higher levels of cognitive and affective empathy one year later among adolescents [42] and experimental work that shows that interdependent Facebook use can promote relational orientation [37], this study contributes to the growing literature on how social media can facilitate positive psychosocial development.

Although promising, there are limitations of the current meta-analysis to consider. This study aimed to look only at global measures of social media use in everyday life and, because of this inclusion parameter, includes a small sample of studies and effect sizes. This likely limits the generalizability of the results and our ability to detect differences by moderators (gender, age). Also, the results are correlational and do not establish causality. Previous research suggests that individuals who are prosocial offline are often prosocial online [29]. Despite our attempts to narrow the scope, there remained variability in the measures of media use and study parameters as indicated by the heterogeneity index. Given the wide range of online activities, future studies should explore how specific behaviors are related to different forms of empathy (e.g., helping strangers vs. family or friends [25]). Additionally, the social media landscape is constantly evolving and this study captures media use as assessed by recent studies in one moment in time. Cultural psychologists suggest that changes in technology use, as part of larger shifting sociodemographic and ecological changes, can shape cultural values and learning environments in ways that directly affect human development across time [43]. 
It is also important to note that all of the studies included, and much of media research in general, have been conducted in industrialized, individualistic countries like the United States. This limited our ability to detect cultural differences. On the one hand, the most popular SNSs are often developed in Western cultures and can reflect the highly individualistic values of their developers and users [37] [44]. On the other hand, the Internet is a "global village" of individuals from various nationalities and cultural backgrounds with nearly $60 \%$ of the online population residing outside of the U.S. [44]. These diverse offline cultural values can be reflected in the online [45]-[52]. Additionally, there may be values and goals specific to the SNS context outside of the values that users bring with them [53]. Previous meta-analyses suggest that the effects of media use may be stronger in non-Western countries [26]. Future research should explore how cultural values in the online and offline interact in shaping development.

Although limited, this meta-analysis provides useful insights into the media-empathy paradox [13]. Additionally, it may be informative in better understanding growing generations of adolescents and young adults who have become the first generations to have grown up fully immersed in digital media (i.e., "digital natives") having been born around or after the 1990s when the Internet was first commercially launched. This may mean that psychosocial development for these "digital natives" differs from prior generations of "digital immigrants" [9]. For example, greater face-to-face communication with family members, close friends, and acquaintances was associated with higher levels of psychological well-being (e.g., life meaning, relationship quality) for older adults age 35 - 54 but not for young adults age 18 - 34 [54]. As technology transforms society, social relationships, and media landscapes, it will become ever important to track how these changes affect individuals and their development.

\section{Conflicts of Interest}

The authors declare no conflicts of interest regarding the publication of this paper.

\section{References}

[1] Davis, M. (1994) Empathy: A Social Psychological Approach. Wm. C. Brown Communications, Inc., Dubuque.

[2] de Waal, F.B. (2010) The Evolution of Empathy. In: Keltner, D., Marsh, J. and Smith, J.A., Eds., The Compassionate Instinct. The Science of Human Goodness, W. W. Norton \& Company, Inc., New York, 16-25.

[3] Masten, C.L., Morelli, S.A. and Eisenberger, N.I. (2011) An fMRI Investigation of Empathy for "Social Pain" and Subsequent Prosocial Behavior. Neuroimage, 55, 381-388. https://doi.org/10.1016/j.neuroimage.2010.11.060

[4] Allemand, M., Steiger, A.E. and Fend, H.A. (2015) Empathy Development in Adolescence Predicts Social Competencies in Adulthood. Journal of Personality, 83, 229-241. https://doi.org/10.1111/jopy.12098

[5] Eisenberg, N. and Miller, P.A. (1987) The Relation of Empathy to Prosocial and Related Behaviors. Psychological Bulletin, 101, 91. 
https://doi.org/10.1037/0033-2909.101.1.91

[6] Twenge, J.M. (2013) The Evidence for Generation Me and against Generation We. Emerging Adulthood, 1, 11-16. https://doi.org/10.1177/2167696812466548

[7] Bach, R.A., Defever, A.M., Chopik, W.J. and Konrath, S.H. (2017) Geographic Variation in Empathy: A State-Level Analysis. Journal of Research in Personality, 68, 124-130. https://doi.org/10.1016/j.jrp.2016.12.007

[8] Chopik, W.J., O’Brien, E. and Konrath, S.H. (2017) Differences in Empathic Concern and Perspective Taking across 63 Countries. Journal of Cross-Cultural Psychology, 48, 23-38. https://doi.org/10.1177/0022022116673910

[9] Prensky, M. (2001) Digital Natives, Digital Immigrants Part 1. On the Horizon, 9, 1-6. https://doi.org/10.1108/10748120110424816

[10] Subrahmanyam, K. and Smahel, D. (2010) Digital Youth: The Role of Media in Development. Springer Science \& Business Media, Bloomington.

[11] Valkenburg, P.M. (2017) Understanding Self-Effects in Social Media. Human Communication Research, 43, 477-490. https://doi.org/10.1111/hcre.12113

[12] Boyd, D.M. and Ellison, N.B. (2007) Social Network Sites: Definition, History, and Scholarship. Journal of Computer-Mediated Communication, 13, 210-230. https://doi.org/10.1111/j.1083-6101.2007.00393.x

[13] Konrath, S. (2012) The Empathy Paradox: Increasing Disconnection in the Age of Increasing Connection. In: Luppicini, R., Ed., Handbook of Research on Technoself. Identify in a Technological Society, IGI Global, Hershey, 204-228.

[14] Konrath, S.H., O’Brien, E.H. and Hsing, C. (2011) Changes in Dispositional Empathy in American College Students over Time: A Meta-Analysis. Personality and Social Psychology Review, 15, 180-198. https://doi.org/10.1177/1088868310377395

[15] Gentile, B., Twenge, J.M. and Campbell, W.K. (2010) Birth Cohort Differences in Self-Esteem, 1988-2008: A Cross-Temporal Meta-Analysis. Review of General Psychology, 14, 261. https://doi.org/10.1037/a0019919

[16] Twenge, J.M. and Campbell, W.K. (2008) Increases in Positive Self-Views among High School Students: Birth-Cohort Changes in Anticipated Performance, Self-Satisfaction, Self-Liking, and Self-Competence. Psychological Science, 19, 1082-1086. https://doi.org/10.1111/j.1467-9280.2008.02204.x

[17] Twenge, J.M. and Foster, J.D. (2010) Birth Cohort Increases in Narcissistic Personality Traits among American College Students, 1982-2009. Social Psychological and Personality Science, 1, 99-106. https://doi.org/10.1177/1948550609355719

[18] Twenge, J.M., Konrath, S., Foster, J.D., Keith Campbell, W. and Bushman, B.J. (2008) Egos Inflating over Time: A Cross-Temporal Meta-Analysis of the Narcissistic Personality Inventory. Journal of Personality, 76, 875-902. https://doi.org/10.1111/j.1467-6494.2008.00507.x

[19] Arnett, J.J. (2013) The Evidence for Generation We and against Generation Me. Emerging Adulthood, 1, 5-10. https://doi.org/10.1177/2167696812466842

[20] Alloway, T., Runac, R., Qureshi, M. and Kemp, G. (2014) Is Facebook Linked to Selfishness? Investigating the Relationships among Social Media Use, Empathy, and Narcissism. Social Networking, 3, 150. https://doi.org/10.4236/sn.2014.33020

[21] Errasti, J., Amigo, I. and Villadangos, M. (2017) Emotional Uses of Facebook and Twitter: Its Relation with Empathy, Narcissism, and Self-Esteem in Adolescence. Psychological Reports, 120, 997-1018. https://doi.org/10.1177/0033294117713496

[22] Valkenburg, P.M. and Peter, J. (2011) Online Communication among Adolescents: An Integrated Model of Its Attraction, Opportunities, and Risks. Journal of Adoles - 
cent Health, 48, 121-127. https://doi.org/10.1016/j.jadohealth.2010.08.020

[23] Uhls, Y.T. and Greenfield, P.M. (2011) The Rise of Fame: An Historical Content Analysis. Cyberpsychology: Journal of Psychosocial Research on Cyberspace, 5, Article 1.

[24] Uhls, Y.T., Zgourou, E. and Greenfield, P.M. (2014) 21st Century Media, Fame, and Other Future Aspirations: A National Survey of 9 - 15 Year Olds. Cyberpsychology: Journal of Psychosocial Research on Cyberspace, 8, Article 5. https://doi.org/10.5817/CP2014-4-5

[25] Coyne, S.M., Padilla-Walker, L.M., Holmgren, H.G., Davis, E.J., Collier, K.M., Memmott-Elison, M.K. and Hawkins, A.J. (2018) A Meta-Analysis of Prosocial Media on Prosocial Behavior, Aggression, and Empathic Concern: A Multidimensional Approach. Developmental Psychology, 54, 331. https://doi.org/10.1037/dev0000412

[26] Liu, D. and Baumeister, R.F. (2016) Social Networking Online and Personality of Self-Worth: A Meta-Analysis. Journal of Research in Personality, 64, 79-89. https://doi.org/10.1016/j.jrp.2016.06.024

[27] Song, H., Zmyslinski-Seelig, A., Kim, J., Drent, A., Victor, A., Omori, K. and Allen, M. (2014) Does Facebook Make You Lonely? A Meta Analysis. Computers in Human Behavior, 36, 446-452. https://doi.org/10.1016/j.chb.2014.04.011

[28] James, C., Davis, K., Charmaraman, L., Konrath, S., Slovak, P., Weinstein, E. and Yarosh, L. (2017) Digital Life and Youth Well-Being, Social Connectedness, Empathy, and Narcissism. Pediatrics, 140, S71-S75. https://doi.org/10.1542/peds.2016-1758F

[29] Reich, S.M. (2017) Connecting Offline Social Competence to Online Peer Interactions. Psychology of Popular Media Culture, 6, 291.

https://doi.org/10.1037/ppm0000111

[30] Davis, M.H. (1983) Measuring Individual Differences in Empathy: Evidence for a Multidimensional Approach. Journal of Personality and Social Psychology, 44, 113. https://doi.org/10.1037/0022-3514.44.1.113

[31] Vossen, H.G., Piotrowski, J.T. and Valkenburg, P.M. (2015) Development of the Adolescent Measure of Empathy and Sympathy (AMES). Personality and Individual Differences, 74, 66-71. https://doi.org/10.1016/j.paid.2014.09.040

[32] Jolliffe, D. and Farrington, D.P. (2006) Development and Validation of the Basic Empathy Scale. Journal of Adolescence, 29, 589-611. https://doi.org/10.1016/j.adolescence.2005.08.010

[33] Reniers, R.L., Corcoran, R., Drake, R., Shryane, N.M. and Völlm, B.A. (2011) The QCAE: A Questionnaire of Cognitive and Affective Empathy. Journal of Personality Assessment, 93, 84-95. https://doi.org/10.1080/00223891.2010.528484

[34] Carrier, L.M., Spradlin, A., Bunce, J.P. and Rosen, L.D. (2015) Virtual Empathy: Positive and Negative Impacts of Going Online upon Empathy in Young Adults. Computers in Human Behavior, 52, 39-48. https://doi.org/10.1016/j.chb.2015.05.026

[35] Chadwick, S. and Ralston, E. (2010) Perspective-Taking in Structured and Unstructured Online Discussions. International Journal of Teaching and Learning in Higher Education, 22, 1-11.

[36] Ang, R.P. and Goh, D.H. (2010) Cyberbullying among Adolescents: The Role of Affective and Cognitive Empathy, and Gender. Child Psychiatry \& Human Development, 41, 387-397. https://doi.org/10.1007/s10578-010-0176-3

[37] Hong, S. and Na, J. (2018) How Facebook Is Perceived and Used by People across Cultures: The Implications of Cultural Differences in the Use of Facebook. Social Psychological and Personality Science, 9, 435-443. 
https://doi.org/10.1177/1948550617711227

[38] Powell, P.A. and Roberts, J. (2017) Situational Determinants of Cognitive, Affective, and Compassionate Empathy in Naturalistic Digital Interactions. Computers in $\mathrm{Hu}$ man Behavior, 68, 137-148. https://doi.org/10.1016/j.chb.2016.11.024

[39] Lorah, J. (2018) Effect Size Measures for Multilevel Models: Definition, Interpretation, and TIMSS Example. Large-Scale Assessments in Education, 6, 8. https://doi.org/10.1186/s40536-018-0061-2

[40] Peterson, R.A. and Brown, S.P. (2005) On the Use of Beta Coefficients in Meta-Analysis. Journal of Applied Psychology, 90, 175. https://doi.org/10.1037/0021-9010.90.1.175

[41] Borenstein, M., Hedges, L.V., Higgins, J.P. and Rothstein, H.R. (2009) Introduction to Meta-Analysis. John Wiley \& Sons, West Sussex. https://doi.org/10.1002/9780470743386

[42] Vossen, H.G. and Valkenburg, P.M. (2016) Do Social Media Foster or Curtail Adolescents' Empathy? A Longitudinal Study. Computers in Human Behavior, 63, 118-124. https://doi.org/10.1016/j.chb.2016.05.040

[43] Greenfield, P.M. (2009) Linking Social Change and Developmental Change: Shifting Pathways of Human Development. Developmental Psychology, 45, 401. https://doi.org/10.1037/a0014726

[44] Singh, N., Zhao, H. and Hu, X. (2005) Analyzing the Cultural Content of Web Sites: A Cross-National Comparison of China, India, Japan, and US. International Marketing Review, 22, 129-146. https://doi.org/10.1108/02651330510593241

[45] Boz, N. and Guan, S.S.A. (2017) "Your Profile Is So Rad": Self-Presentation Strategies in Turkish Adolescents. The European Journal of Communication Research, 42, 23-46.

[46] Chen, W. (2010) Internet-Usage Patterns of Immigrants in the Process of Intercultural Adaptation. Cyberpsychology: Behavior, and Social Networking, 13, 387-399. https://doi.org/10.1089/cyber.2009.0249

[47] Jackson, L.A. and Wang, J.L. (2013) Cultural Dif0000ferences in Social Networking Site Use: A Comparative Study of China and the United States. Computers in Human Behavior, 29, 910-921. https://doi.org/10.1016/j.chb.2012.11.024

[48] Na, J., Kosinski, M. and Stillwell, D.J. (2015) When a New Tool Is Introduced in Different Cultural Contexts: Individualism-Collectivism and Social Network on Facebook. Journal of Cross-Cultural Psychology, 46, 355-370. https://doi.org/10.1177/0022022114563932

[49] Mazur, E. and Li, Y. (2016) Identity and Self-Presentation on Social Networking Web Sites: A Comparison of Online Profiles of Chinese and American Emerging Adults. Psychology of Popular Media Culture, 5, 101. https://doi.org/10.1037/ppm0000054

[50] Qiu, L., Lin, H. and Leung, A.K.Y. (2013) Cultural Differences and Switching of In-Group Sharing Behavior between an American (Facebook) and a Chinese (Renren) Social Networking Site. Journal of Cross-Cultural Psychology, 44, 106-121. https://doi.org/10.1177/0022022111434597

[51] Xu, J., Yang, T., Cong, T. and Zeng, Y. (2015) Use of Social Networking Sites among Chinese and American Researchers: A Comparative Study. Journal of Scholarly Publishing, 47, 60-76. https://doi.org/10.3138/jsp.47.1.03

[52] Xu, Y. and Zhang, W. (2017) New Media's Impact on China from a Culture Perspective. In: New Media and Chinese Society, Springer, Singapore, 95-119. 
https://doi.org/10.1007/978-981-10-6710-5_6

[53] Meyrowitz, J. (1986) No Sense of Place: The Impact of Electronic Media on Social Behavior. Oxford University Press, New York.

[54] Chan, M. (2014) Multimodal Connectedness and Quality of Life: Examining the Influences of Technology Adoption and Interpersonal Communication on Well-Being across the Life Span. Journal of Computer-Mediated Communication, 20, 3-18. https://doi.org/10.1111/jcc4.12089 